\title{
Oculomotor control in Gilles de la Tourette syndrome
}

\author{
E L BOLLEN,* RAC ROOS, * A P COHEN, $\dagger$ RB MINDERAA, $\ddagger$ JPH REULEN, \\ B J M VAN DE WETERING, \| TCA M VAN WOERKOM, $†$ O S BURUMA* \\ From the Department of Neurology, University Hospital Leiden,* Psychiatric Centre Rosenburg, Department of \\ Neuropsychiatry, The Hague, $\dagger$ Sophia Children's Hospital, Erasmus University, $\ddagger$ Rotterdam, Department of \\ Medical Physics, Free University of Amsterdam,§ Amsterdam, Department of Psychiatry, University Hospital \\ Rotterdam-Dijkzigt, $\|$ Rotterdam
}

SUMMARY Saccadic eye movements, fixation and smooth pursuit were studied in 28 children with Gilles de la Tourette syndrome and found to be normal. A link has been postulated between Gilles de la Tourette syndrome and other movement disorders. The results obtained in the present series do not support this hypothesis.

Gilles de la Tourette syndrome is a disorder characterised by multiple motor and vocal tics. Patients are able to suppress their tics for minutes to hours. Over periods varying from weeks to months, the intensity of tics shows a waxing and waning course. The onset of symptoms is in childhood. ${ }^{1-3}$ Forced gaze deviation and blepharospasm, common in progressive supranuclear palsy and in Huntington's disease, ${ }^{56}$ are frequently observed in Gilles de la Tourette syndrome. It has been suggested that this common symptomatology may indicate a link between the syndrome and progressive supranuclear palsy and Huntington's disease. ${ }^{4}$ Moreover, oculomotor abnormalities are known to be an important cause of failure in ability to perform tasks requiring eye-hand coordination. ${ }^{5}$ As neuropsychological examination has revealed disturbances of such abilities in Gilles de la Tourette syndrome, ${ }^{7}$ oculomotion was studied in this condition

\section{Patients}

Twenty-eight children ( 21 boys, 7 girls) with Gilles de la Tourette syndrome were examined (mean age, 11.2 years; age range, 8 to 15 years). The patients entering the study came from the Department of Neuropsychiatry, Psychiatric Centre "Rosenburg" The Hague, the outpatients clinics of

Address for reprint requests: Dr E L Bollen, Department of Neurology, University Hospital Leiden, P.O. Box 9600, 2300 RC Leiden, The Netherlands.

Received 24 April 1987 and in revised form 12 January 1988. Accepted 1 March 1988 the Sophia Children's Hospital Rotterdam, and the Department of Neurology of the University Hospital Leiden. All patients met the DSM III (DSM III, 1980) ${ }^{8}$ diagnostic criteria and the criteria defined by Shapiro. ${ }^{1}$ Nineteen patients used low doses of the following drugs: clonidine (12 patients), pimozide (7), haloperidol (1), fluphenazine (1) or pipamperonchloride (dipiperon) (1). Three patients were on a combination of drugs and the remaining nine patients were medication free.

\section{Methods}

Eye movements were measured with a newly developed infrared reflection technique combined with a computerised portable eye movement processing system. ${ }^{9-12}$ The eye movement measuring device was incorporated in a spectacle frame attached to the head. Accordingly, eye position was measured with respect to head position. Head movement did not interfere with the measuring properties of the technique. With a bandwidth of D.C. to $100 \mathrm{~Hz}(-3 \mathrm{~dB})$ the resolution of the IR technique is $2 \mathrm{~min}$ arc in both horizontal and vertical directions. The system is linear within $3 \%$ for eyerotation up to $20^{\circ}$ horizontally and up to $14^{\circ}$ vertically, measured from the centre position. The drift of the IRtechnique is negligible, so that it does not disturb the DCmode used to record eye position. The movement of both eyes was measured simultaneously while patients were sitting in a room with low level of ambient illumination. Whenever patients were not able to prevent head movements, despite a support at the back of their head, one of the investigators gently stabilised the head with his hands. In this set-up, the target for saccades consisted of an array of red galliumarsenide light-emitting diodes (LED) of wavelength $635 \mathrm{~nm}$, mounted in a black cylindrical screen. Each diode subtended a visual angle of $0.16^{\circ}$ at a viewing distance of $1.5 \mathrm{~m}$. If 

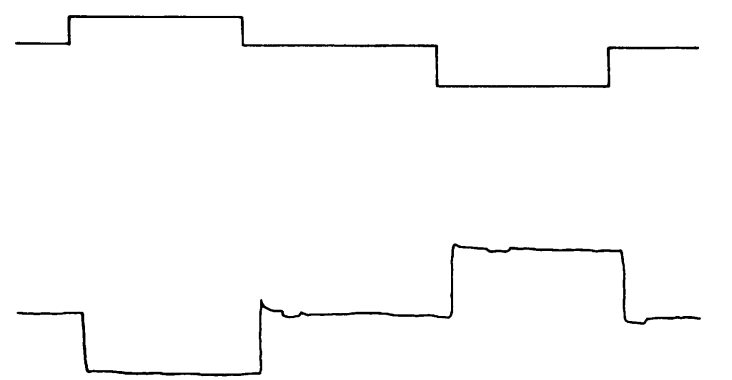

Fig 1 Normal saccades towards a visual target in a patient with Gilles de la Tourette syndrome. Upper trace: target, amplitude $20 \cdot 1^{\circ}$. Lower trace: saccadic eye movements with normal latency and normal peak velocity. Saccades to the right: upward deflection, saccades to the left: downward deflection.

viewed from a distance of $1.5 \mathrm{~m}$, the peripheral target spots were located $6.7^{\circ}, 13.4^{\circ}$ and $20.1^{\circ}$ to the left or right of the primary fixation position at the centre of the screen. Rotation of the screen through $90^{\circ}$ provided similar stimulus locations in the vertical direction. The LEDs were controlled by a Z80-based microcomputer ${ }^{13}$ via programmable LED drivers. The maximum target luminance was about $3 \mathrm{log}$ units above the foveal threshold level.

To study voluntary saccades, two stationary targets (double target), symmetrically located with respect to the centre of the screen were simultaneously and constantly lit. The patient was asked to alternate fixation between these double targets. Saccades performed in this way were called voluntary saccades (fig 1).

To study visually evoked saccades, randomly selected target steps of variable amplitude to the left or right of the primary central fixation position were generated by extinguishing the central LED and illuminating a peripheral one. The time between two successive peripheral stimuli was varied at random between 2 and $4 \mathrm{~s}$, so that the patient was unaware precisely when or where the peripheral stimulus was going to occur. Patients were instructed to change fixation from the central target to the peripheral spot presented for $2 \mathrm{~s}$ as quickly and accurately as possible. These saccades in response to simple target steps were called visually evoked saccades. The peripheral target was then extinguished and the central target simultaneously relit, evoking a saccade back to the primary position of gaze. Because of the predictable occurrence of the return saccade, data on it were not included in latency studies.

The appearance of unwanted saccades towards distracting visual stimuli was studied by asking the patients to fixate on the central LED and to ignore the appearance of peripheral, distracting visual stimuli presented with similar random timing and positioning as mentioned before. During presentation of the peripheral target, the central fixation spot remained lit. Unwanted saccades towards distracting visual stimuli were defined as saccades that were performed despite the instruction to fixate on the central LED and that brought the eye to the position of the peripheral stimulus. Undershoot dysmetria giving rise to multiple step saccades interspersed by an intersaccadic time interval, was classified as a single unwanted saccade and only so if the final target position was reached. The number of the saccades was counted and expressed as a percentage of the total number of distracting stimuli presented.

Normal values of saccadic latency, peak velocity and frequency of unwanted saccades were compared with normal values previously established in our laboratory. Normal values of saccadic eye movements are as follows: latency maximal (mean +2SD) $270 \mathrm{~ms}$, peak velocity minimal (mean - 2SD) $135^{\circ} / \mathrm{s}\left(6.7^{\circ}\right.$ amplitude), $260^{\circ} / \mathrm{s}\left(13.4^{\circ}\right.$ amplitude) and $300^{\circ} / \mathrm{s}\left(20 \cdot 1^{\circ}\right.$ amplitude). Frequency of unwanted saccades towards distracting visual stimuli is $10 \%$ or less of the frequency of the distracting stimuli.

Fixational square-wave jerks larger than $1^{\circ}$ in amplitude and at a frequency above 10/min were considered abnormal. ${ }^{14}$ They were counted and expressed as number/s. Macro-square-wave jerks were defined as having an amplitude above $7^{\circ}$. Despite the occurrence of square-wave-jerks during fixation, reliable calibration of eye position was possible in all patients.

Patients were kept alert by verbal encouragement. After each tenth stimulus, a short break was introduced to avoid fatigue.

In the statistical evaluation the sign test and the Spearman rank correlation test were used.

Smooth pursuit was evoked by a target moving along a line through the fovea. A laser beam was reflected on to a screen by a mirror galvanometer mounted on an optical scanner servomotor. The scanner system is driven by software running in a Z80-based microprocessor system. Sinusoidal stimuli with peak-to-peak amplitude of $24^{\circ}$ and with frequencies of $0.1,0.3,0.5$ and $0.7 \mathrm{~Hz}$ were selected Smooth pursuit gain of less than 0.95 was considered abnormal.

\section{Results}

During the test performance, one patient did not cooperate and was therefore omitted. Of the
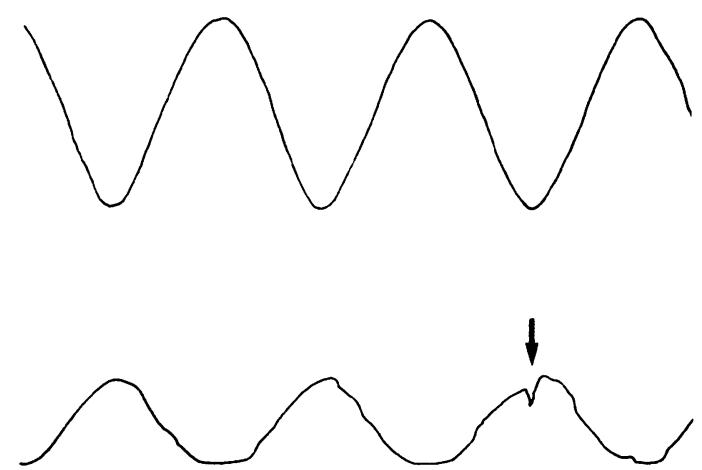

Fig 2 Normal smooth pursuit in a patient with Gilles de la Tourette syndrome. Upper trace: target, frequency $0.5 \mathrm{~Hz}$, peak-to-peak amplitude: $24^{\circ}$. Lower trace: smooth pursuit tracking, gain 0.96. Note interruption of smooth pursuit tracking by tic (arrow). 
remaining 27 patients, latency and peak velocity of voluntary saccades and of visually evoked saccades were normal. No multiple step saccades and no hypermetria were seen. Fixation was normal; no square wave jerks and no unwanted saccades towards distracting stimuli during fixation occurred.

Smooth pursuit showed no abnormalities. Smooth pursuit gains were normal for all the target frequencies tested (fig 2).

No differences were found between medicated and unmedicated patients.

\section{Discussion}

Saccadic eye movements, fixation of a midline and an eccentric target, and smooth pursuit were normal in our children. Of particular interest in our patients is the absence of unwanted saccades towards distracting visual stimuli. The substantia nigra pars reticulata inhibits saccade related cells in the superior colliculi and in this way prevents the occurrence of unwanted saccades towards visual stimuli. ${ }^{1516}$ This inhibitory function of the substantia nigra pars reticulata is thought to be the main basal ganglia output modulating saccadic eye movements. ${ }^{17}$ In contrast to Huntington's disease, where unwanted saccades towards distracting visual stimuli occur with abnormally high frequency, ${ }^{8918}$ the inhibitory neostriatal output appears to be normal in Gilles de la Tourette syndrome. Therefore, despite the fact that the clinical findings in Gilles de la Tourette syndrome in some aspects may be comparable to those in Huntington's disease and progressive supranuclear palsy, ${ }^{4}$ our results do not support a link between Gilles de la Tourette syndrome and these movement disorders. Furthermore the disabilities revealed in neuropsychological tests in Gilles de la Tourette syndrome ${ }^{7}$ appear not to be due to oculomotor disturbances.

A variety of centrally acting drugs has been shown to impair various aspects of oculomotion in man. ${ }^{19}$ Low doses of neuroleptics as given to our patients appear to have had no effect on eye movement parameters.

\section{References}

I Shapiro AK, Shapiro ES, Bruun RD, Sweet RD. Gilles de la Tourette Syndrome. New York. Raven Press, 1978.

2 Singer HS, Butier IJ, Tiene LE, Seifert WE and Coyle
JT. Dopaminergic dysfunction in Tourette syndrome. Ann Neurol 1982;12:361-6.

3 Lees AJ. Tics and Related Disorders Edinburgh, 1985. Churchill and Livingstone.

4 Frankel M, Cummings JL. Neuro-ophthalmic abnormalities in Tourette's syndrome: functional and anatomic implications. Neurology 1984;34:359-61.

5 Fisk JD, Goodale MA, Burkhart G, Barnett HJM. Progressive supranuclear palsy: the relationship between ocular motor dysfunction and psychological test performance. Neurology 1983;33:698-705.

6 Bruyn GW, Went LN. Huntington's chorea. In: Vinken PJ, Bruyn GW, Klawans HL (eds.). Handbook of Clinical Neurology. Rev. Series 5, Vol. 49., Amsterdam Elsevier Sci. Publ., 1986;267-314.

7 Barnstein RA, King G, Carroll A. Neuropsychological abnormalities in Gilles de la Tourette's syndrome, J Nerv Ment Dis 1983;171:497-502.

8 DSM III. Diagnostic and Statistical Manual of Mental Disorders ed III. Washington DC. American Psychiatric Association. 1980.

9 Bollen E, Reulen JPH, Den Heyer JC, Roos RAC, Buruma OJS. Oculomotor disturbances in Huntington's chorea. $J$ Neurol Sci 1986;74:11-22.

10 Reulen JPH, Van Heuningen R, Tiesinga G, Bos JE. A computerised eye movement processor for clinical application. Med Biol Eng Comput 1986;24:209-15.

11 Reulen JPH, Marcus JT, Koops D et al. Precise recording of eye movements: the IRIS system. Med Biol Eng Comput. (In press).

12 Reulen JPH, Sanders EACM, Hogenhuis LAH. Eye movement disorders in multiple sclerosis and optic neuritis. Brain 1983;106:121-40.

13 Goovaerts HG, Van Veen C, Meekes MAAM. A general purpose microprocessor system for medical instrumentation and electrical stimulation. J Biomed Eng 1984;6:89-96.

14 Herishanu Y, Sharpe JA. Normal Square wave jerks. Invest Ophthalmol Vis Sci 1981;20:268-72.

15 Hikosaka O, Wurtz RH. Modification of saccadic eye movements by GABA-related substances. I. Effect of muscimol and bicuculline in monkey superior colliculus. J Neurophysiol 1985;53:266-91.

16 Hikosaka O, Wurtz RH. Modification of saccadic eye movements by GABA-related substances. II. Effects of muscimol in monkey substantia nigra pars reticulata. J Neurophysiol 1985;53:292-308.

17 Hotson JR, Langston EB, Langston JW. Saccade responses to dopamine in human MPTP-induced parkinsonism. Ann Neurol 1986;20:456-63.

18 Leigh R, Newman S, Folstein S, Lasker A, Jensen B. Abnormal oculomotor control in Huntington's disease. Neurol 1983;33:1268-75.

19 Tedeschi G, Bittencourt PRM, Smith AT, Richens A. Specific oculomotor deficits after amylobarbitone. Psychopharmacology 1983;79:187-9. 